\title{
AS PROPOSTAS CURRICULARES DE GEOGRAFIA PARA A EDUCAÇÃO BÁSICA DO PARANÁ A PARTIR DA DÉCADA DE 1990
}

\author{
The curricular proposals of Geography for the basic education of Paraná from the 1990s
}

\author{
Lesete Kaveski Rutecki* \\ Valdivânia Pereira Barbosa** \\ ** Mestranda do PPG em Geografia, UNICENTRO - lkaveski@unicentro.br \\ ** Mestranda do PPG em Educação, UNICENTRO - valdivaniabarbosa@yahoo.com.br
}

Recebido em 03/08/2018. Aceito para publicação em 25/08/2018.

Versão online publicada em 20/11/2018 (http://seer.ufrgs.br/paraonde)

\begin{abstract}
Resumo:
O presente trabalho é resultado de pesquisa bibliográfica e documental tendo abrangido os Currículos de Geografia para os anos finais do Ensino Fundamental. São eles, o Currículo Básico para a Escola Pública do Paraná, os Parâmetros Curriculares Nacionais e as Diretrizes Curriculares Orientadoras da Educação Básica para a Educação Básica, implementados no estado do Paraná, a partir da década de 1990. No período em questão, ocorreram significativas transformações na educação, sobretudo, na área de currículos escolares, que recebeu grande influência dos organismos internacionais. Como resultado da pesquisa, percebemos que as propostas curriculares de Geografia apresentam concepções distintas entre si, haja vista, o contexto histórico em que cada uma foi produzida.
\end{abstract}

Palavras-chave: Currículo; Geografia; Políticas educacionais.

\begin{abstract}
The present work is a result of bibliographical and documentary research having covered the Geography Programs for the final years of Elementary School. These are the Basic Curriculum for the Public School of Paraná, the National Curricular Parameters and the Guidelines for Basic Education for Basic Education, implemented in the state of Paraná, from the 1990s. During the period in question, there were significant changes in education, especially in the area of school programs, which received great influence from international organizations. As a result of the research, we noticed that the curricular plans of Geography present different conceptions of each other, given the historical context in which each was produced.
\end{abstract}

Key-words: Curriculum; Geography; Educational policies.

\section{Introdução}

0 presente trabalho é resultado de uma pesquisa documental sobre os currículos de Geografia a partir da década de 1990, período em que ocorreram significativas transformações na educação, principalmente pelo fato de ter sido marcado pelas políticas neoliberais. A área de currículos escolares recebeu grande influência dos organismos internacionais. A definição dos rumos da formação dos trabalhadores é de interesse, principalmente, do sistema de produção capitalista, pois é preciso se adequar às transformações no mundo do trabalho e a escola, por meio do currículo, colabora para o cumprimento desse papel.

A reestruturação curricular no Paraná, teve início em 1987. Mas, foi somente em 1990 que o Currículo Básico para a Escola Pública do Estado do Paraná foi publicado, contemplando as diversas áreas do conhecimento. A Geografia, nesse documento, se apresenta numa perspectiva crítica e propõe o desenvolvimento dos conteúdos a partir do materialismo histórico dialético.

Em 1998, foi publicada uma nova proposta de reorientação curricular para todo o território 
brasileiro. Esse documento, intitulado Parâmetros Curriculares Nacionais (PCN), foi elaborado pelo Ministério da Educação e é destinado ao Ensino Fundamental.

Em 2003, no Estado do Paraná, teve início um movimento de reformulação curricular, que resultou na publicação das Diretrizes Curriculares Orientadoras da Educação Básica do Paraná, as DCE. O documento, assumiu uma estrutura curricular disciplinar, fundamentado na ideia de conteúdos estruturantes para todas as disciplinas escolares.

Sendo assim, analisamos as três propostas curriculares: Currículo Básico para a Escola Pública do Estado do Paraná, os Parâmetros Curriculares Nacionais (PCN) e as Diretrizes Curriculares Orientadoras da Educação verificando as concepções, metodologia, avaliação e conteúdos referente a disciplina Geografia.

\section{Breve histórico das propostas curriculares no contexto paranaense}

A palavra currículo Segundo Zotti (2016), vem do latim Scurrere e, de forma bastante simples, pode significar corrida ou caminho a percorrer. Entende-se que se trata de um conjunto de matérias a serem cursadas, conteúdos a serem "percorridos" num determinado tempo. Compreende também os procedimentos, técnicas e recursos a serem utilizados para se desenvolver o processo.

Lopes (2013), aponta que há registros do termo que datam de 1633, na Universidade de Glasgow, na Escócia, correspondendo ao curso seguido pelos estudantes. A autora relata que, até o século XIX, os conteúdos que são próprios de cada disciplina guardavam em si a sua utilidade e ao desenvolverem o raciocínio lógico e a ampliação da memória já cumpriam a sua função.

Porém, currículo pode significar mais do que um rol de disciplinas com seus conteúdos específicos e orientações metodológicas a serem seguidas. Ao estudar a questão curricular, importa saber porque determinados conteúdos e não outros constam nos currículos, em quais contextos são elaborados e as teorias que os influenciaram, que sujeitos pretendem formar, os impactos da implementação e a formação resultante.

No Brasil, conforme Rocha (2003), os estudos curriculares tiveram início nos anos de 1930. Baseado nos estudos de Antônio Flávio Moreira, o autor afirma, que as origens do pensamento curricular se fundamentaram nas ideias escolanovistas. Rocha (2003) destaca a importância que teve o INEP (Instituto Nacional de Estudos Pedagógicos) e o PABAEE (Programa de Assistência Brasileiro-Americana ao Ensino Elementar). Esse último, trouxe significativa influência americana para o campo do currículo em processo no Brasil.

Outros pensamentos pedagógicos se destacaram no período. Saviani (2013), esclarece que, ao criticar a educação burguesa e formular a sua própria concepção pedagógica, os ideais anarquistas, ligados ao movimento operário insurgente no final do século XIX e início do século XX, também tiveram papel importante e deram origem a dezenas de escolas.

Porém, foi nas primeiras décadas do século XX que as discussões sobre currículo ganham mais força com o processo de industrialização e a necessidade de se pensar o ensino para essa sociedade emergente.

Na segunda metade do século XX, as ideias pedagógicas também foram influenciadas pelo educador Paulo Freire e a chamada educação popular que tinha como foco ascender a participação política das massas e a tomada de consciência da realidade brasileira. (SAVIANI, 2013).

Nos anos 1980, período de reestruturação democrática no Brasil, ocorreram reformas significativas no campo dos currículos, principalmente nas regiões sul e sudeste:

As reformas curriculares geradas nesse contexto foram, de modo geral, marcadas pelo discurso que dava ênfase à necessidade de recuperar a relevância social dos conteúdos veiculados na escola, contrapondo-se às orientações tecnicistas que prevaleceram na década anterior. (BARRETO, 1998, p. 8).

Ainda segundo Barretto (1998), a pedagogia crítico-social dos conteúdos passou a ganhar espaço na elaboração de currículos oficiais. Para essa pedagogia, deve-se dar destaque às características e as necessidades das classes populares assegurando-lhes condições de lutar por

Para0nde!?, Porto Alegre, v.10, n.2, p.01-07, 2018. Edição Especial com artigos publicados originalmente na XII ENANPEGE http://seer.ufrgs.br/paraonde 
direitos e por uma sociedade mais justa, pensamento que coadunava com o momento político e social brasileiro.

Na década de 1990, ocorreram significativas transformações na educação e o currículo ganhou bastante destaque. As reformas educacionais ocorridas na década de 1990, se intensificaram a partir da Conferência Mundial de Educação para Todos, realizada em Jomtien, na Tailândia. 0 evento foi convocado pela Organização das Nações Unidas para a Educação, a Ciência e a Cultura (UNESCO), pelo Fundo das Nações Unidas para a Infância (UNICEF), pelo Programa das Nações Unidas para o Desenvolvimento (PNUD) e pelo Banco Mundial (BIRD). Os reflexos do encontro, que reuniu representantes de 155 países, culminou com a publicação da Lei de Diretrizes e Bases da Educação Nacional (LDB no 9394/1996), os Parâmetros Curriculares Nacionais e as Diretrizes Curriculares Nacionais (SILVA, 2008).

Vemos, então, que definir os rumos da formação dos trabalhadores interessa, principalmente, ao sistema de produção capitalista. Assim, torna-se necessário adequar a educação às transformações no mundo do trabalho. 0 currículo, objeto de disputa, de acordo com Ciavatta \& Ramos (2012); Frigotto \& Ciavatta (2003), reflete as intenções dos diferentes segmentos da sociedade. Além dos agentes sociais e políticos locais, agentes globais também influenciam a educação e os currículos.

Na rede pública de educação do Estado do Paraná, nestas duas últimas décadas, também ocorreram mudanças no que se refere à elaboração de propostas curriculares. A partir de 1987, se iniciou um processo de reestruturação curricular que resultou na publicação do documento intitulado Currículo Básico para a Escola Pública do Estado do Paraná, em 1990. Esta proposta, direcionada à então Pré-escola e ao Ensino de 1ํㅡ Grau, hoje Educação Infantil e Ensino Fundamental, não provocou "avanços significativos, especialmente porque foram poucos os momentos de formação continuada que contribuíram para a sua consolidação. " (HIDALGO et al, 2010, p. 26).

A partir do ano de 2003, teve início, no estado do Paraná, um movimento de reformulação curricular que resultou na publicação das Diretrizes Curriculares Orientadoras da Educação Básica do Paraná, as DCE. Este documento se apresenta como "configurador da prática, vinculando-se às teorias críticas", e ainda, como fruto do Currículo Básico de 1990, que se fundamentava no materialismo histórico dialético (SEED, 2008, p.19). Para Hidalgo et al (2010), a mudança dos grupos que atuam na Secretaria de Educação a cada gestão e as ideias e concepções do mundo acadêmico influenciam no resultado das propostas curriculares imprimindo-lhes suas marcas. Ainda que no contexto da elaboração do Currículo Básico a discussão do materialismo histórico e dialético tenha sido considerada e nas atuais DCE se tenha feito um esforço para seguirem a mesma linha teórica, isso não foi possível no conjunto das disciplinas escolares.

\section{Considerações sobre os currículos escolares de geografia no Paraná}

Desde o ano de 1990, foram implementadas três propostas curriculares na rede escolar paranaense: o Currículo Básico para a Escola Pública do Estado do Paraná (1990), os Parâmetros Curriculares Nacionais (1998) e as Diretrizes Curriculares Orientadoras da Educação Básica (2008).

A Geografia, ao longo de sua inserção nos currículos escolares, passou por mudanças teóricometodológicas significativas, assim como as teorias que influenciaram na elaboração dos currículos nas últimas décadas.

O Currículo Básico para a Escola Pública do Estado do Paraná (CB), visando a melhoria do ensino no sentido de responder às necessidades sociais e históricas que caracterizavam a sociedade brasileira na década de 1980, declara nos textos introdutórios, a opção pela pedagogia históricocrítica (PARANÁ, 1990).

Na proposta de Geografia que compõe este documento, em consonância com os demais textos do $\mathrm{CB}$, é destacada a opção

[...] pelo ensino de uma geografia crítica, que desvele a realidade, uma geografia que conceba o espaço geográfico como sendo um espaço social, produzido e reproduzido pela sociedade humana, com vistas a nele se realizar e se reproduzir." (PARANÁ, 1990, p. 99).

Para0nde!?, Porto Alegre, v.10, n.2, p.01-07, 2018. Edição Especial com artigos publicados originalmente na XII ENANPEGE http://seer.ufrgs.br/paraonde 
No texto dos Parâmetros Curriculares Nacionais de Geografia, por sua vez, encontramos críticas à Geografia Tradicional e à Geografia Marxista. Para os elaboradores dos PCN, essas duas correntes negligenciaram [...] "a dimensão sensível de perceber o mundo" [...]. (BRASIL, 1998, p. 22).

Dessa forma, nos PCN, as categorias de análise da Geografia (lugar, paisagem, região e território) são resgatadas, dando destaque às [...] "relações entre o processo histórico na formação das sociedades humanas e o funcionamento da natureza por meio da leitura do lugar, do território, a partir da paisagem." (BRASIL, 1998, p. 26). Ao dar ênfase, principalmente, ao lugar e à paisagem, os PCN de Geografia valorizam as abordagens que consideram as dimensões subjetivas, os significados atribuídos ao lugar ou à paisagem que o indivíduo percebe.

Nos PCN, os conteúdos se separam em conceituais, atitudinais e procedimentais. Apresentam também, o trabalho com os chamados temas transversais, que são "questões importantes, urgentes e presentes sob várias formas, na vida cotidiana." (BRASIL, 1997, p.15).

As Diretrizes Curriculares Orientadoras da Educação Básica, DCE, elegem o espaço geográfico como o objeto de estudo da Geografia, "entendido como espaço produzido e apropriado pela sociedade" (LEFEBVRE apud PARANÁ, 2008, p. 51). Este documento

também destaca a importância dos conceitos básicos (ou categorias de análise) da Geografia, quais sejam, lugar, paisagem, região, território e, diferentemente dos PCN, traz ainda como conceitos básicos sociedade e natureza.

Nas DCE, é proposta uma análise do espaço geográfico, objeto de estudo da Geografia, considerando os conceitos/categorias sob o método dialético. (PARANÁ, 2008, p. 52). Diferente das demais propostas curriculares, as DCE apresentam, para todas as disciplinas, os Conteúdos Estruturantes, "conhecimentos de grande amplitude que identificam e organizam os campos de estudos de uma disciplina escolar, considerados fundamentais para a compreensão de seu objeto de estudo e ensino" (idem, p.69).

Selecionamos nos quadros 01, 02 e 03 alguns conteúdos, encaminhamentos metodológicos e formas de avaliação presentes nas propostas analisadas.

\section{QUADRO 01 - CONTEÚDOS SELECIONADOS}

\section{Conteúdos}

\section{Currículo Básico}

\section{Parâmetros Curriculares}

Nacionais

\section{Diretrizes Curriculares}

Fonte: BRASIL (1997); PARANÁ (1990); BRASIL (2008)

Org.: BARBOSA , V. P.; RUTECKI, L. K. (2017)
- A divisão internacional do trabalho e o avanço geográfico do capitalismo;

- A industrialização e o processo de urbanização nos países capitalistas;

- A revolução industrial e a questão ambiental

- A nova divisão internacional do trabalho e as redes de cidades mundiais;

- A urbanização no período técnico-científico informacional, a automação e problema do desemprego;

- Progressos técnico-científicos mediando as relações sociedade/natureza

- A dinâmica da natureza e a sua alteração pelo emprego de tecnologias de exploração e produção.

Para0nde!?, Porto Alegre, v.10, n.2, p.01-07, 2018. Edição Especial com artigos publicados originalmente na XII ENANPEGE http://seer.ufrgs.br/paraonde 


\section{QUADRO 02 - ENCAMINHAMENTOS METODOLÓGICOS}

\section{Encaminhamentos metodológicos}

\section{Currículo Básico}

\section{Parâmetros \\ Curriculares Nacionais}

\section{Diretrizes Curriculares}

Fonte: BRASIL (1997); PARANÁ (1990); BRASIL (2008) Org.: BARBOSA, V. P.; RUTECKI, L. K. (2017)

\section{QUADRO 03 - AVALIAÇÃO}

\section{Currículo Básico}

\section{Parâmetros Curriculares Nacionais}

\section{Diretrizes Curriculares}

Fonte: BRASIL (1997); PARANÁ (1990); BRASIL (2008)

Org.: BARBOSA, V. P.; RUTECKI, L. K. (2017)
- Parte sempre do entendimento do modo de produção capitalista para explicar os processos que influenciam na organização espacial.

- "Abordagem humanista-plural e sociocultural". (p.96);

- Observação, descrição, representação explicação e compreensão do espaço; analogias - Recursos didáticos:

- Estudo do meio, uso de imagens, fontes documentais, música, dramatização, pesquisa, literatura, jornais, estabelecer comparações, entre outros.

Abordagem vinculada aos Conte Estruturantes em suas dimensões: econômica, política, socioambiental, cultural e demográfica.

Práticas pedagógicas: Aulas de campo, recursos áudio visuais, cartografia, literatura.

\section{Avaliação}

- Considera a educação como transformação social; - Mecanismo de diagnóstico da situação para pensar a prática e a ela se retornar;

- Dois eixos a serem avaliados: as transformações que se processam a partir do trabalho e a maneira como os homens organizam e produzem o espaço (p. 120121).

Por critérios: conceituais, procedimentais e atitudinais.

Avaliar numa perspectiva de conclusão de uma fase da escolaridade (p. 128).

Concepção de avaliação formativa (p. 86). Critérios: formação dos conceitos geográficos básicos, entendimento das relações socioespaciais. Indica instrumentos: interpretação e produção de textos, imagens, gráficos, tabelas e mapas, pesquisas, relatórios, seminários, maquetes, e outros. 
Embora as teorias que embasam cada documento curricular sejam distintas as propostas de conteúdos, encaminhamentos metodológicos e formas de avaliação da aprendizagem se assemelham em vários aspectos.

\section{Considerações Finais}

A partir da análise das três propostas curriculares implementadas no estado do Paraná, a partir da década de 1990, podemos tecer algumas considerações sobre os documentos. Podemos observar que as propostas curriculares apresentam concepções distintas, haja vista o contexto histórico em que foram produzidas, mas, também guardam algumas similaridades. A Geografia, desde a sua institucionalização como ciência, até o período da elaboração das propostas curriculares em questão, passou por mudanças teórico-metodológicas importantes, o que influenciou na produção dos documentos analisados.

O Currículo Básico para a Escola Pública do Estado do Paraná e as Diretrizes Curriculares Orientadoras da Educação Básica guardam algumas semelhanças na concepção. Porém, no texto do CB, os autores procuram ser fiéis à concepção pedagógica (histórico-crítica) desde o conceito da disciplina à abordagem dos conteúdos. Neste documento, os autores não sugerem práticas pedagógicas e sim a forma de abordar o conteúdo, pela via do materialismo histórico-dialético. As DCE, por sua vez, trazem uma forma diferente de abordar os conhecimentos geográficos por meio dos Conteúdos Estruturantes e sugerem várias práticas pedagógicas.

Os PCN apresentam uma concepção de Geografia distinta das propostas curriculares paranaenses. Neste documento, a concepção de Geografia prioriza a percepção do sujeito sobre a realidade com destaque para os estudos do lugar e da paisagem. Vários conteúdos sugeridos são semelhantes entre os PCN, as DCE e o Currículo Básico.

\section{Referências}

BARRETO, E. S. Tendências recentes do currículo no ensino fundamental no Brasil. In: BARRETO, E. S. (Org.). Os currículos do Ensino Fundamental nas Escolas Brasileiras. São Paulo: Autores Associados/Fundação Carlos Chagas, 1998.

BRASIL. Secretaria de Educação Fundamental. Parâmetros curriculares nacionais: apresentação dos temas transversais - Ética / Secretaria de Educação Fundamental. - Brasília: MEC/SEF, 1997.

BRASIL. Ministério da Educação e do Desporto. Secretaria de Educação Fundamental. Parâmetros curriculares nacionais: Geografia. Brasília: MEC/SEF, 1998.

CIAVATTA, M.; RAMOS, M. A "era das diretrizes": a disputa pelo projeto de educação dos mais pobres. In: Revista Brasileira de Educação, v. 17, n. 49, jan.-abr. 2012.

FRIGOTTO, G.; CIAVATTA, M. Educação básica no Brasil na década de 1990: subordinação ativa e consentida à lógica de mercado. In: Educação e sociedade, v. 24, no 82. CampinasSP: 2003.

HIDALGO, Ângela Maria et. al. Pluralismo metodológico nas diretrizes curriculares no Paraná. Guarapuava: Unicentro, 2010.

LOPES, A.C. MACEDO, E. Teorias de currículo. São Paulo: Cortez, 2013.

Para0nde!?, Porto Alegre, v.10, n.2, p.01-07, 2018. Edição Especial com artigos publicados originalmente na XII ENANPEGE http://seer.ufrgs.br/paraonde 
PARANÁ. Secretaria de Estado da Educação. Currículo Básico para a Escola Pública do Estado do Paraná. Curitiba: SEED-PR, 1990.

Secretaria de Estado da Educação. Diretrizes Curriculares Orientadoras da Educação Básica. Geografia. Curitiba: SEED-PR, 2008.

ROCHA, G. O. R. da. A pesquisa sobre currículo no Brasil e a história das disciplinas escolares. In: GONÇALVES, L. A. O. Currículo e políticas públicas. Belo Horizonte: Autêntica, 2003.

SAVIANI, D. História das ideias pedagógicas no Brasil. Campinas, SP: Autores Associados, 2013.

SILVA, M. R. da, ABREU, C. B. de M. Reformas para quê? As políticas educacionais no anos de 1990, o "novo projeto de formação" e os resultados das avaliações nacionais. Perspectiva. Florianópolis, v. 26, no 2, 523-550, jul./dez., 2008. Disponível em:

http://www.perspectiva.ufsc.br Acesso em: 12/01/2017.

ZOTTI, S. A. Currículo. In: LOMBARDI, J.C.; SAVIANE, D.; NASCIMENTO, M. I. M. (Orgs.) Navegando pela História da Educação Brasileira. Campinas - SP. Graf. FE: HISTEDBR, 2006. Disponível em: http://www.histedbr.fe.unicamp.br/navegando/glossario/verb c curriculo.htm 